\title{
Infestação pelo mosquito Aedes aegypti (Diptera: Culicidae) na cidade de Chapecó - SC
}

\author{
Junir Antonio Lutinski ${ }^{1,2 *}$ \\ Bárbara Zanchet ${ }^{2}$ \\ Carin Guarda ${ }^{2}$ \\ Caroline Constanci ${ }^{2}$ \\ Deise Vanessa Friedrich ${ }^{2}$ \\ Fatima Terezinha Castro Cechin ${ }^{2}$ \\ Indiana Alegransi Bones ${ }^{2}$ \\ Marciana Frigeri de Souza ${ }^{2}$ \\ Samara Tessaro Balsan ${ }^{2}$ \\ Suzana Marta Zarychta ${ }^{2}$ \\ Maria Assunta Busato ${ }^{2}$

\begin{abstract}
${ }^{1}$ PPG em Biodiversidade Animal da Universidade Federal de Santa Maria
${ }^{2}$ Programa de Educação pelo Trabalho (PET Saúde, Vigilância em Saúde)

Ministério da Saúde e Universidade Comunitária da Região de Chapecó

* Autor para correspondência

junir@unochapeco.edu.br

Rua Beija-Flor, 254 E, Efapi, CEP 89809-760, Chapecó - SC, Brasil
\end{abstract}

Submetido em 30/11/2012

Aceito para publicação em 14/03/2013

\section{Resumo}

A dengue se tornou um problema de saúde pública e vem causando preocupação aos profissionais de saúde. Este estudo visou a avaliar os fatores condicionantes para a ocorrência de dengue na cidade de Chapecó - SC. Foram analisadas as informações disponíveis no Sistema de Informações de Febre Amarela e Dengue (SISFAD) e foi realizada uma pesquisa a partir de um questionário semiestruturado aplicado à população. As análises indicam a associação da infestação pelo mosquito transmissor da dengue com o lixo inadequadamente tratado e com os depósitos de captação de água da chuva, assim como com o ambiente residencial. A prevenção à dengue no município de Chapecó envolve a implantação de políticas públicas de educação ambiental em saúde para a separação e destinação adequada dos resíduos sólidos e melhorias no sistema de abastecimento público de água. Campanhas educativas voltadas aos cuidados no ambiente domiciliar também são necessárias.

Palavras-chave: Aedes aegypti; Educação ambiental; Resíduos sólidos

\section{Abstract}

Infestation by the Aedes aegypti (Diptera: Culicidae) mosquito in the town of Chapeco, Santa Catarina, Brazil. Dengue fever became a public health problem and it has caused concern among health 
professionals. This study aimed to evaluate the conditioning factors for the occurrence of dengue fever in the town of Chapeco, Santa Catarina, Brazil. One analyzed the information available on the Information System on Yellow Fever and Dengue Fever (SISFAD) and conducted a survey through a semi-structured questionnaire applied to the population. The analyses indicate the association of infestation by the mosquito which transmits dengue to improperly handled garbage and to the rainwater collection deposit, as well as to the residential environment. The prevention of dengue in the town of Chapeco involves the implementation of public policies on health environmental education for proper separation and disposal of solid waste and improvements in the public water supply system. Educational campaigns aimed at care in the home environment are also needed.

Key words: Aedes aegypti; Environmental education; Solid waste

\section{Introdução}

A dengue se tornou um problema de saúde pública sendo responsável por causar epidemias principalmente em regiões tropicais, onde condições sociais, climáticas, ecológicas e ambientais favorecem a proliferação do vetor contribuindo com a circulação viral (SOUZA; LEITE, 2010). Considerada uma doença infecciosa viral, seu agente etiológico é um vírus RNA, arbovírus do gênero Flavivirus, transmitido pelo mosquito Aedes aegypti, cuja espécie é a mais importante na transmissão da doença (BRASIL, 2002).

A incidência de dengue vem crescendo consideravelmente nas últimas décadas em todo mundo. Dados da Organização Mundial da Saúde (OMS, 2012) apontam que mais de 2,5 bilhões de pessoas (mais de $40 \%$ da população mundial), estão propensas a contrair dengue, sendo estimadas de 50 a 100 milhões de infecções pela doença a cada ano. Nas Américas, Sudeste Asiático e Pacifico Ocidental o número de casos excedeu 1,2 milhões em 2008 e mais de 2,2 milhões em 2010 com tendências de aumento destes números a cada ano. Somente em 2010 foram registrados, nas Américas, aproximadamente 49.000 casos de Febre Hemorrágica de Dengue.

Com relação aos dados de notificações de dengue no Brasil, Siqueira Jr. et al. (2010) afirmam que em 2008 foram notificados mais de 637 mil casos de dengue em todo pais, observando-se uma redução em 2009 quando foram registrados, aproximadamente, 411 mil casos. A transmissão da doença voltou a crescer ultrapassando a casa de um milhão de casos em todo o Brasil em 2010. Entre janeiro e abril de 2012 foram notificados aproximadamente 286 mil casos da doença no país (BRASIL, 2012).
No Estado de Santa Catarina o número de casos da doença vem crescendo anualmente, segundo a Diretoria de Vigilância Epidemiológica do Estado (DIVE/SC, 2012). Em 2011, foram registrados 669 casos suspeitos, sendo que destes, 130 foram confirmados, dois com transmissão autóctone e os demais de pessoas que contraíram a doença fora do Estado, mas que foram atendidos e diagnosticados em municípios catarinenses.

Dentre os fatores condicionantes para o desenvolvimento da doença pode-se destacar as condições inadequadas de moradia, o destino incorreto de resíduos sólidos urbanos, a intermitência no abastecimento de água, as precárias condições de infraestrutura urbana e a gestão incorreta lixo. O crescimento urbano gera concentração de indivíduos, tanto suscetíveis à contaminação quanto os já infectados, facilitando o aumento no número de casos da doença. Esse fato, aliado às condições precárias de saneamento básico, à moradia inadequada e a fatores culturais e educacionais proporcionam condições favoráveis à transmissão do vírus da dengue (CUNHA et al., 2008; MACHADO et al., 2009; FREITAS et al., 2011; OLIVEIRA; AMARAL, 2011).

No Estado de Santa Catarina, nos últimos quatro anos, os fatores condicionantes que têm apresentado maior prevalência para o desenvolvimento do mosquito transmissor têm sido o lixo (recipientes plásticos e latas) com 39\% dos focos encontrados, pneus inservíveis com 23\% e pequenos depósitos de água com 19\%. Sobre o tipo de imóvel, 32\% dos criadouros foram igualmente encontrados em residências e pontos estratégicos tais como ferrosvelhos, borracharias, cemitérios e floriculturas, e comércios com 28\% (DIVE/SC, 2012). 
O município de Chapecó vem apresentando nos últimos anos a maior infestação do Estado de Santa Catarina, o que vem preocupando a Vigilância em Saúde do município (FUCK et al., 2010). Diante do exposto, o objetivo deste estudo foi avaliar os fatores condicionantes para a transmissão viral da dengue no município de Chapecó, Santa Catarina.

\section{Material e Métodos}

O Município de Chapecó está localizado na região Oeste do Estado de Santa Catarina, a uma latitude de $27^{\circ} 05^{\prime} 47^{\prime \prime}$ e a uma longitude de $52^{\circ} 37^{\prime} 06^{\prime \prime}$, possuindo uma altitude média de $670 \mathrm{~m}$ em relação ao nível do mar. Segundo dados do Instituto Brasileiro de Geografia e Estatística de 2010, o município possui 183.530 habitantes e uma área urbana aproximada de $113,24 \mathrm{~km}^{2}$ (IBGE, 2010; CHAPECÓ, 2012).

\section{Coleta dos dados}

Esta pesquisa foi documental, quantitativa e teve como fonte de dados o Sistema de Informações de Febre Amarela e Dengue (SISFAD) relativo ao período de janeiro de 2008 a novembro de 2012. Também foi desenvolvido estudo através da aplicação de um questionário semi-estruturado a 137 famílias residentes em sete bairros da cidade, tendo sido entrevistada uma pessoa por família. A partir do questionário buscouse identificar condicionantes ambientais associados à proliferação do mosquito $A$. aegypti.

Este estudo foi desenvolvido como uma das ações do Programa de Educação pelo Trabalho, Vigilância em Saúde (PET Saúde/VS) do Ministério da Saúde. As visitas a campo para aplicação dos questionários foram realizadas por um grupo de estudantes de diferentes cursos da área da saúde da Universidade Comunitária da Região de Chapecó (UNOCHAPECÓ), sob a orientação de professores (tutores) e profissionais da saúde (preceptores), nos meses de janeiro e fevereiro de 2012. As entrevistas contaram com o apoio dos Agentes Comunitárias de Saúde das Estratégias de Saúde da Família e também das Agentes de Combate à Endemias.
O esforço amostral foi de $100 \%$ dos dados contidos no SISFAD relativos à infestação segundo o tipo de imóvel e o tipo de depósito registrados para o município de Chapecó no período avaliado. A evolução da infestação expressa em focos (registros de ocorrências de larvas ou de mosquitos adultos em um dado criadouro, em um dado imóvel) do A. aegypti foi tabulada e expressa graficamente, através do programa Excel for Windows ${ }^{\circledR}$. As frequências anuais de focos, segundo o tipo de imóvel e conforme o tipo de criadouro foram agrupadas em dendogramas, utilizando-se para isso a distância euclidiana com Unweighted pair group method with arithmetic mean (UPGMA) dos dados, realizada através do software Statistica v. 8 (STATSOFT SOUTH AMERICA, 2012). Dentre os tipos de imóveis avaliados, os pontos estratégicos são caracterizados como estabelecimentos comerciais ou industriais que oferecem uma grande quantidade de possíveis locais para a proliferação do mosquito $A$. aegypti (DIVE/SC, 2012).

Os resultados relativos à presença de criadouros no imóvel como caixas de água aberta, cisternas, piscina sem tratamento, pneus a céu aberto, lixo e calhas de edificações foram registradas segundo a presença ou ausência. Todos os resultados foram tabulados em um banco de dados construído com o aplicativo Excel for Windows ${ }^{\circledR}$ e posteriormente analisados no Statistical Package for the Social Sciences (SPSS INCORPORATION, 2012). Nessa análise foram obtidas as frequências relativas e percentuais para as variáveis avaliadas.

A utilização das fontes de dados do SISFAD contou com a autorização prévia do gestor da Secretaria da Saúde do município.

Para a construção e aplicação dos questionários foram observados todos os aspectos éticos, assegurando o pleno consentimento dos entrevistados, sigilo de identidade e garantia de que nenhuma exposição fosse proporcionada aos entrevistados. O questionário foi aprovado juntamente com o projeto pelo Comitê de Ética em Pesquisa (CEP) da Universidade Comunitária da Região de Chapecó sob número 274/2010. 


\section{Resultados}

Os resultados relativos à infestação de $A$. aegypti mostram uma oscilação anual no número de focos registrados no município. Em 2008 foram identificados 175 focos, baixando para 90 em 2009 e crescendo novamente em 2010 quando foram registrados 232. Em 2011, houve um novo declínio chegando a 155 e em 2012 voltou a crescer significativamente, alcançando 495 focos até o mês de novembro (Figura 1).
A evolução do número de focos de $A$. aegypti, segundo o tipo de imóvel, mostrou que o maior número de focos foi encontrado nas residências, exceto no ano de 2011, onde houve um aumento do número de focos nos ambientes comerciais. Os terrenos baldios apresentaram o terceiro tipo de imóvel com maior número de criadouros, seguido por pontos estratégicos (locais onde há grande concentração de depósitos preferenciais para a desova do A. aegypti) e outros imóveis (Figura 2).

FIGURA 1: Evolução anual do número de focos do mosquito Aedes aegypti notificados para o município de Chapecó, SC (2008 a novembro de 2012).

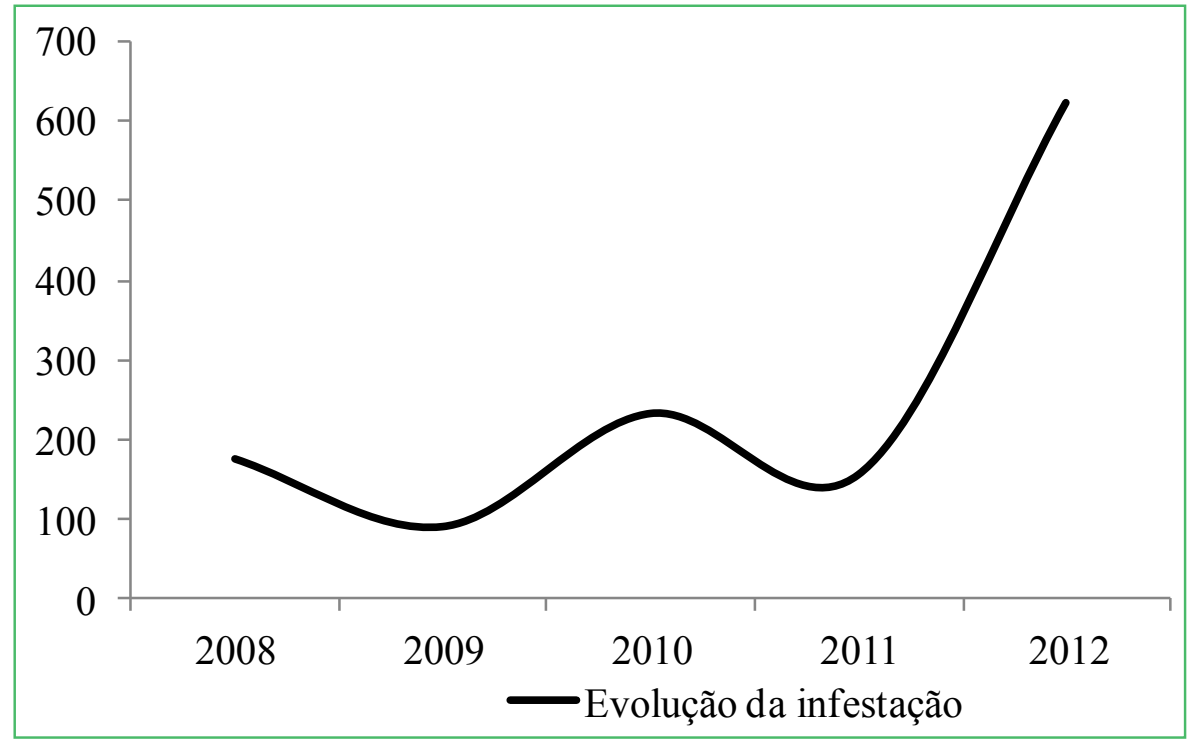

FIGURA 2: Evolução anual do número de focos de $A$. aegypti segundo o tipo de imóvel no município de Chapecó no período de 2008 a novembro de 2012 (C: comércios; R: residências; TB: terrenos baldios; PE: pontos estratégicos; O: outros).

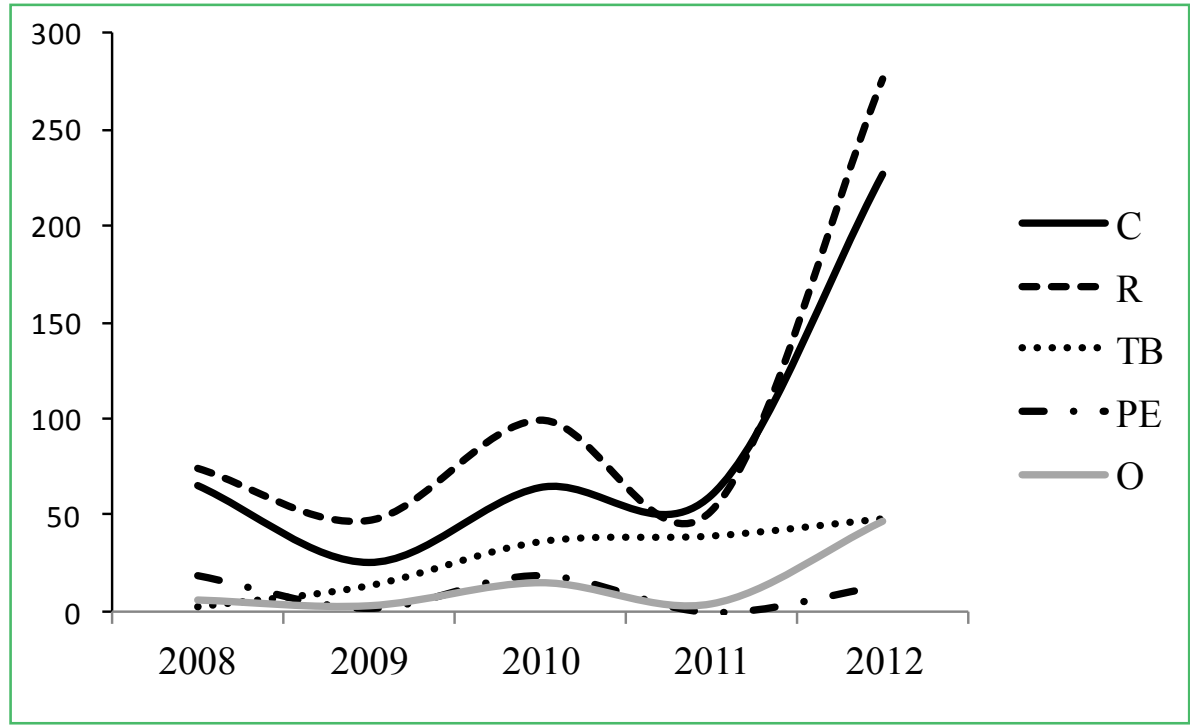


A análise de agrupamento da infestação, segundo o tipo de imóvel, mostrou que imóveis residenciais e comerciais apresentaram similaridade entre si quanto a infestação enquanto que estes apresentaram significativa dissimilaridade de terrenos baldios, pontos estratégicos e os demais tipos de imóveis (outros) (Figura 3).

Os resultados da evolução dos focos de $A$. aegypti, segundo o tipo de criadouro, mostram que o lixo apresentou o maior número de focos em todo o período avaliado. Os depósitos móveis, juntamente com os depósitos de água ao nível do solo (cisternas) se destacaram como os maiores criadouros depois do lixo. Criadouros como pneus, piscinas, caixas de água elevadas e depósitos naturais apresentaram as menores frequências de focos (Figura 4).

A análise de dissimilaridade da infestação, segundo os tipos de depósitos, evidenciou que o lixo (D2) se destacou em um grupo isolado de todos os demais. A

FIGURA 3: Análise de agrupamento da infestação de $A$. aegypti segundo os tipos de imóveis no município de Chapecó no período de 2008 a abril de 2012 (C: comércios; R: residências; TB: terrenos baldios; PE: pontos estratégicos; O: outros).

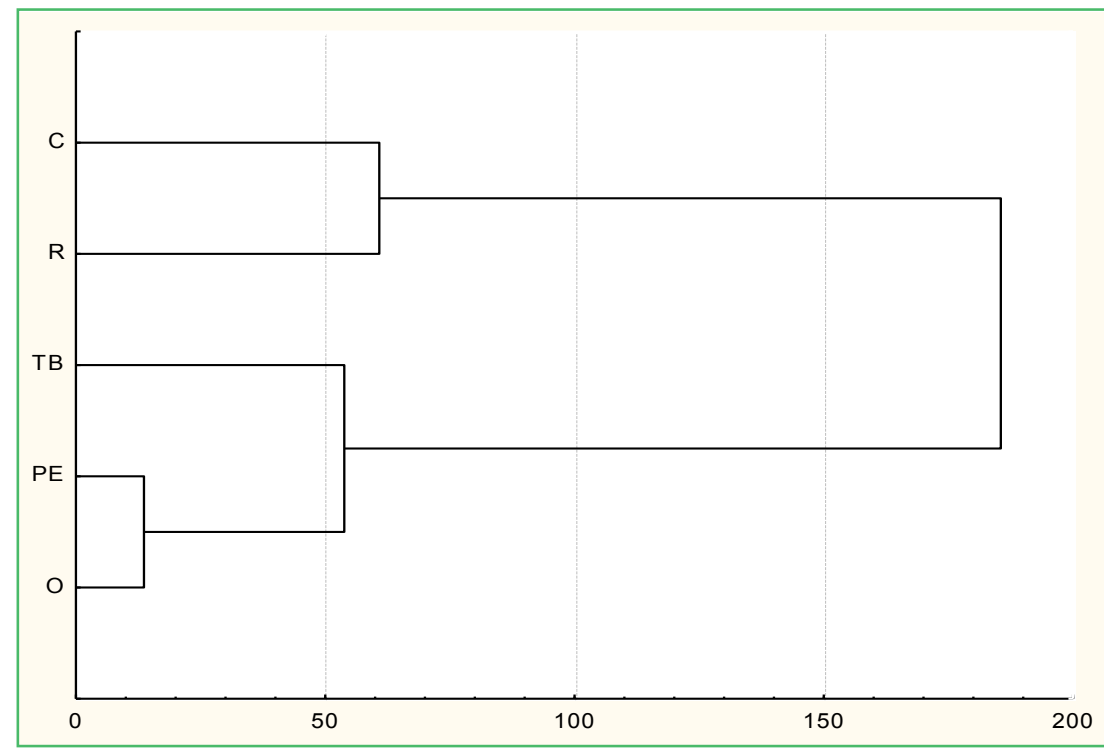

FIGURA 4: Evolução anual do número de focos de $A$. aegypti segundo o tipo de criadouro no município de Chapecó no período de 2008 a novembro de 2012 (A1: caixas de água; A2: cisternas; B: depósitos móveis; C: piscinas; D1: pneus; D2: lixo; E: depósitos naturais).

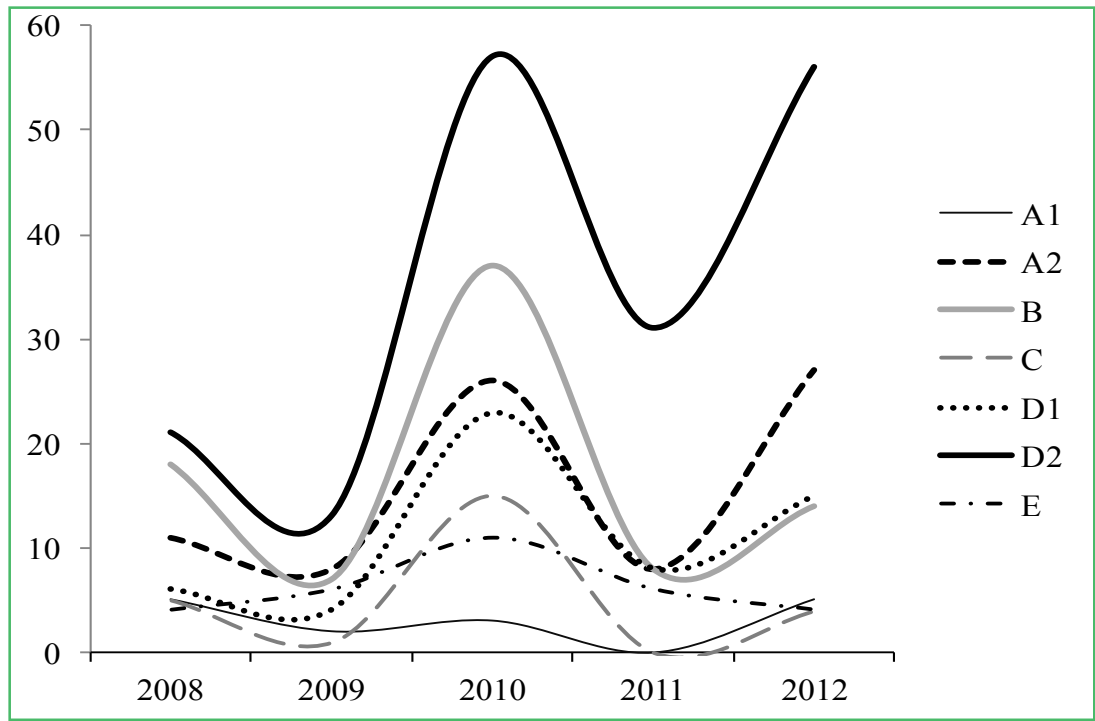


análise apresentou ainda dois agrupamentos com menor dissimilaridades entre si: um formado por caixas de água (A1), Piscinas (C) e criadouros naturais (E) e outro formado por cisternas (A2), pneus (D1) e depósitos móveis (B) (Figura 5).

Os resultados das entrevistas relativos à presença de potenciais criadouros para o A. aegypti confirmaram o que se observou na evolução dos focos no município como um todo, ou seja, que o lixo abandonado corresponde ao tipo de reservatório mais encontrado nos quintais e pátios, seguido da presença de caixas de água, calhas, pneus, cisternas e piscinas. Um percentual pequeno $(<5 \%)$ representou aqueles imóveis nos quais não foi possível identificar a presença ou a ausência (Sem identificação) dos criadouros em potencial (Figura 6).

FIGURA 5: Análise de similaridade para a infestação de $A$. aegypti segundo os tipos de criadouros no município de Chapecó no período de 2008 a abril de 2012 (A1: caixas de água; A2: cisternas; B: depósitos móveis; C: piscinas; D1: pneus; D2: lixo; E: depósitos naturais).

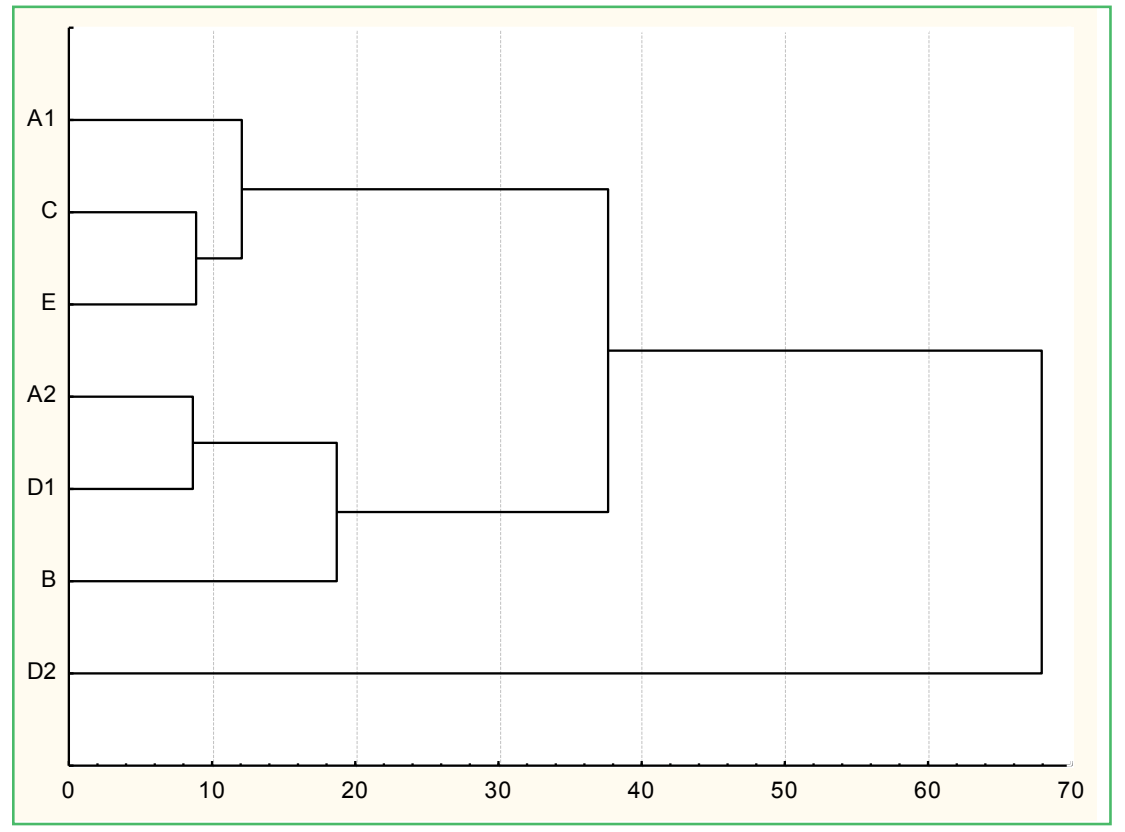

FIGURA 6: Frequência relativa percentual da presença de potenciais criadouros para o desenvolvimento de focos de larvas de $A$. aegypti em residências do município de Chapecó no período de janeiro e fevereiro 2012.

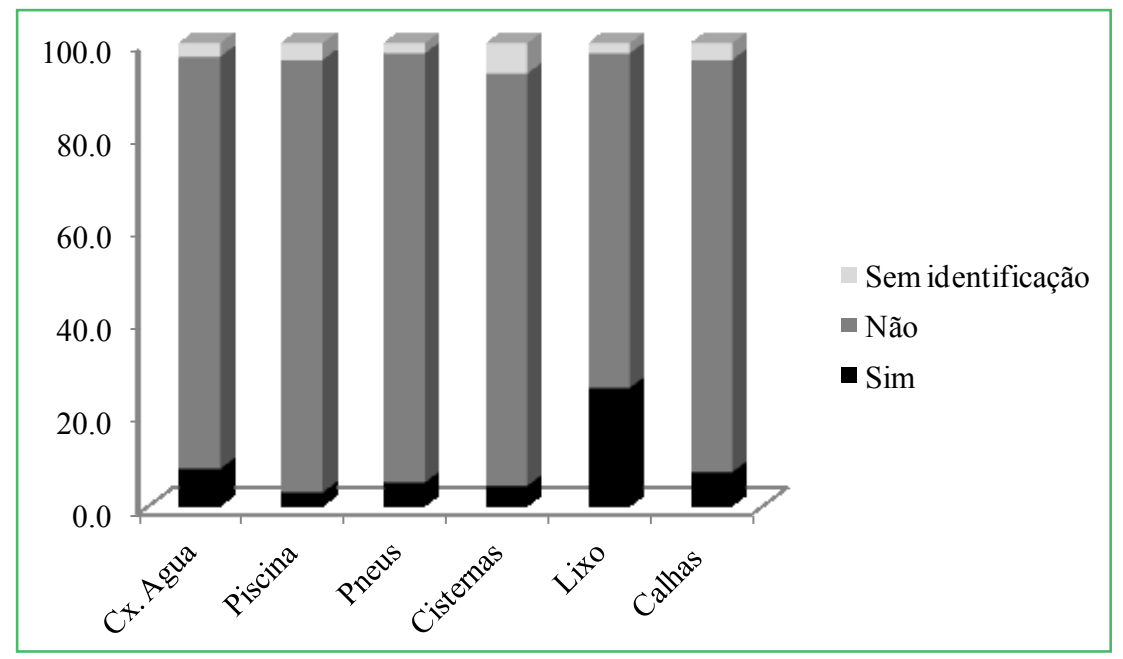




\section{Discussão}

A dengue é uma arbovirose que tem causado preocupação por ser considerada um problema de saúde pública mundial. Os países tropicais são os mais atingidos em função de suas características ambientais, climáticas e sociais. A expansão das áreas de ocorrência de dengue no mundo e no Brasil está associada tanto à urbanização desordenada quanto à globalização da economia. Tais fatores contribuem não só para a dispersão ativa do mosquito como também para a disseminação dos vários sorotipos da doença (RIBEIRO et al., 2006).

Esta pesquisa mostra que um dos tipos de imóvel onde mais foram encontrados criadouros de A. aegypti foram as residências. $\mathrm{O}$ maior desafio na prevenção à dengue tem sido evitar a formação de criadouros do vetor nos espaços privados, em particular, nos espaços domésticos onde os profissionais de saúde encontram dificuldade de acesso e de atuação (TAUIL, 2002). Ainda, de acordo com Tauil (2002), a resistência à visita oferecida pela população se explica pala intervenção do Agente de Controle de Endemias no ambiente privado da família, através de eliminação de objetos, fazendo as devidas ponderações e solicitando ou alertando sobre determinados hábitos que os membros daquela família possuem. Este fator torna-se preocupante, pois grande parte dos criadouros está dentro das residências, em vasos de plantas, garrafas, latas e outros (SILVA, et al., 2008; TEIXEIRA, 2008; CAZOLA et al., 2011).

Os terrenos baldios se destacaram como o terceiro tipo de imóvel com maior número de criadouros. Isso ocorre porque o lixo não coletado geralmente é depositado pela população em áreas públicas ou terrenos baldios, aumentando o número de potenciais criadouros (PIGNATTI, 2002). São necessárias mudanças de comportamento associadas à percepção que a população tem sobre o problema, de forma que sejam adotados hábitos que evitem a presença e a reprodução do $A$. aegypti de forma geral (CAZOLA et al., 2011).

A evolução dos focos de A. aegypti, segundo o tipo de criadouro, mostrou que o lixo representou a maior causa de proliferação do mosquito em todo o período avaliado. O acúmulo de lixo é incompatível com as políticas de prevenção de zoonoses e o seu depósito em áreas peridomiciliares leva ao acúmulo de recipientes que servem de reservatórios do vetor da dengue, particularmente nos meses chuvosos do ano. A destinação do lixo doméstico torna-se um problema, pois sua coleta é muitas vezes irregular ou não é feita nas áreas de mais difícil acesso, levando os moradores a improvisar maneiras de se desfazerem do lixo, depositando-o em terrenos e encostas desocupados. A realidade encontrada pela pesquisa não é diferente quando analisamos outros estudos presentes na literatura. Há uma relação positiva entre o acúmulo de lixo e a manifestação da dengue, necessitando uma mudança de comportamento da população em relação à correta gestão do lixo doméstico (PIGNATTI, 2002; CLARO et al., 2004; LEFEVRE et al., 2007).

No presente estudo, criadouros como pneus, piscinas, caixas de água elevadas e depósitos naturais apresentaram as menores frequências de focos. Porém os cuidados preventivos com estes criadouros não devem ser esquecidos, pois os grandes reservatórios de água são classificados como de alto risco para a proliferação do vetor da dengue e também contribuem para que a área em que este se localiza fique infestada. Especialmente as caixas d'água configuram-se, nessa condição, pois mantêm seu volume constante e geralmente estão localizadas sobre as residências, local de difícil acesso para a inspeção entomológica (NUNES et al., 2010).

É importante expor que os resultados sobre a presença de potenciais criadouros para o desenvolvimento de A. aegypti nas residências dos entrevistados apresentaram percentuais relativamente baixos para os itens como piscinas, pneus e cisternas. Entretanto, a presença de lixo foi verificada em um percentual de aproximadamente $25 \%$ dos imóveis visitados seguido pelas caixas d'água $(\cong 10 \%)$ e calhas $(\cong 8 \%)$. Este fato, associado à presença de outros potenciais criadouros mesmo que em percentuais menores, configuram uma situação de risco para a manifestação do vetor. Esta pesquisa demonstrou que $92 \%$ das pessoas entrevistadas e residentes no território que contém a maior infestação do mosquito $A$. aegypti, são alfabetizados, o que permite pressupor que essa população tenha condições e discernimento para entender e compreender as campanhas educativas promovidas pelo município 
para a prevenção da doença, para reconhecer possíveis criadouros do mosquito transmissor e também para a tomada de ações preventivas a fim de evitar reprodução do mosquito. No entanto, isso se contrapõe aos achados deste estudo que mostram o crescimento elevado da ocorrência de focos do mosquito, anualmente. Neste sentido, percebe-se uma lacuna entre a informação e a ação que se reflete no esquecimento do papel individual na promoção da saúde coletiva.

A prevenção à dengue passa pela importante incorporação de determinados hábitos no cotidiano da população e do poder público, sobre como evitar potenciais reservatórios de água em quintais, a manutenção de piscinas com água tratada, a separação e coleta regular de lixo, o abastecimento permanente de água encanada e educação ambiental em saúde (TAUIL, 2001)

A elevada infestação pelo mosquito transmissor no município de Chapecó, ao longo dos anos, reflete as fragilidades do município no abastecimento de água, nas políticas públicas efetivas de educação ambiental e na coleta seletiva. Fatores que tem levado a população a buscar sistemas alternativos de suprimento e armazenamento de água, na maioria das vezes sem os cuidados necessários, que falham no objetivo de fomentar e encorajar a participação social nas ações e cuidados no ambiente domiciliar, especialmente na reciclagem do lixo doméstico que, como demonstrado no estudo, é o principal locus criadouro do mosquito.

\section{Agradecimentos}

À Universidade Comunitária da Região de Chapecó pelo apoio ao projeto. Às Secretarias de Saúde de Santa Catarina e do município de Chapecó, pelo apoio e acesso aos bancos de dados. Aos coordenadores e profissionais dos Centros de Saúde do município, pela colaboração. Às Agentes Comunitárias de Saúde e Agentes de Combate a Endemias, pelo apoio na realização da coleta de dados da pesquisa e a comunidade que participou e colaborou nas entrevistas. Apoio financeiro: Programa de Educação pelo Trabalho PET Saúde Vigilância em Saúde do Ministério da Saúde.

\section{Referências}

BRASIL - MINISTÉRIO DA SAÚDE. SECRETARIA DE POLÍTICAS DE SAÚDE. DEPARTAMENTO DE ATENÇÃO BÁSICA. Dermatologia na atenção básica/Ministério da Saúde, Secretaria de Políticas de Saúde. 1. ed. Brasília: Ministério da Saúde, 2002.

BRASIL - MINISTÉRIO DA SAÚDE. Balanço Dengue. 2012. Disponível em: <http://portalsaude.saude.gov.br/portalsaude/ arquivos/ap_balnco_dengue.pdf $>$. Acesso em: 19 fev. 2013.

CAZOLA, L. H. O.; PONTES, E. R. J. C.; TAMAKI, E. M. O Controle da dengue em duas áreas urbanas do Brasil Central: percepção dos moradores. Saúde e Sociedade, São Paulo, v. 20, n. 3, p. 786-796, 2011.

CHAPECÓ. Banco de dados do município. 2012. Disponível em: $<$ http://www.chapeco.sc.gov.br/prefeitura/portal/>. Acesso em: 1 fev. 2012.

ClARO, L. B. L.; TOMASSINI, H. C. B.; ROSA, M. L. G. Prevenção e controle do dengue: uma revisão de estudos sobre conhecimentos, crenças e práticas da população. Cadernos de Saúde Pública, Rio de Janeiro, v. 20, n. 6, p. 1447-1457, 2004.

CUNHA, M. C. M.; CAIAFFA, W. T.; OLIVEIRA, C. L.; KROON, E. G.; PESSANHA, J. E. M.; LIMA, J. A.; PROIETTI, F. A. Fatores associados à infecção pelo vírus do dengue no Município de Belo Horizonte, Estado de Minas Gerais, Brasil: características individuais e diferenças intra-urbanas. Revista Epidemiologia e Serviços de Saúde, Brasília, v. 17, n. 3, p. 217-230, 2008.

DIVE/SC - DIRETORIA DE VIGILÂNCIA EPIDEMIOLÓGICA. SECRETÁRIADE ESTADO DA SAÚDE: SUPERINTENDÊNCIA DE VIGILÂNCIA EM SAÚDE. Informações Dengue. Florianópolis: Diretoria de Vigilância Epidemiológica, 2012.

FREITAS, R. M.; RODRIGUES, C. S.; ALMEIDA, M. C. M. Estratégia intersetorial para o controle da dengue em Belo Horizonte (Minas Gerais), Brasil. Saúde e Sociedade, São Paulo, v. 20, n. 3, p. 773-785, 2011.

FUCK, J. A. B.; TESTON, M.; AZZOLINI, I. L. G.; SILVEIRA, L. Avaliação das ações do programa de controle da dengue em municípios selecionados do oeste catarinense. Revista de Saúde Pública de Santa Catarina, Florianópolis, v. 3, n. 2, p. 6-19, 2010.

IBGE. Instituto Brasileiro de Geografia e Estatística. 2010. Disponível em: <http://www.ibge.gov.br/cidadesat/default.php>. Acesso em: 5 fev. 2012.

LEFEVRE, A. M. C.; RIBEIRO, A. F.; MARQUES, G. R. A. M.; SERPA, L. L. N.; LEFEVRE, F. Representações sobre dengue, seu vetor e ações de controle por moradores do município de São Sebastião, litoral Norte do Estado de São Paulo, Brasil. Cadernos de Saúde Pública, Rio de Janeiro, v. 23, n. 7, p. 1696-1706, 2007.

MACHADO, J. P.; OLIVEIRA, R. M.; SOUZA-SANTOS, R. Análise espacial da ocorrência de dengue e condições de vida na cidade de Nova Iguaçu, Estado do Rio de Janeiro, Brasil Spatial analysis of dengue occurrence and living conditions in Nova Iguaçu, Rio de Janeiro State, Brazil. Cadernos de Saúde Pública, Rio de Janeiro, v. 25, n. 5, p. 1025-1034, 2009.

NUNES, L. L. S.; ARDUINO, M. B.; MARQUES, G. R. A. M.; RAMOS, D. G. Prevenção da dengue: implicações do uso de tela no controle de Aedes aegypti em reservatórios de água para consumo humano. Bepa, São Paulo, v. 7, n. 80, p. 4-9, 2010. 
OLIVEIRA, E. S.; AMARAL, L. P. Estudo da relação dos fatores climáticos e casos de dengue no município de Assis Chateaubriand, Paraná. Engenharia Ambiental, Espírito Santo do Pinhal, v. 8, n. 2, p. 171-181, 2011.

OMS - ORGANIZAÇÃO MUNDIAL DA SAÚDE. Dengue and severe dengue. 2012. Disponível em: <http://www.who.int/ mediacentre/factsheets/fs117/en/index.html>. Acesso em: 10 abr. 2012.

PIGNATTI, M. G. Políticas ambientais e saúde: as práticas sanitárias para o controle do dengue no ambiente urbano. Cuiabá: Instituto de Saúde Coletiva, 2002. p. 1-12.

RIBEIRO, A. F.; MARQUES, G. R. A. M.; VOLTOLINI, J. C.; CONDINO, M. L. F. Associação entre incidência de dengue e variáveis climáticas. Revista de Saúde Pública, São Paulo, v. 40, n. 4 p. 671-676, 2006.

SILVA, S. J.; MARIANO, Z. F.; SCOPEL, I. A dengue no Brasil e as políticas de combate ao Aedes aegypti: da tentativa de erradicação ás políticas de controle. Hygeia, Uberlândia, v. 3, n. 6, p. 163-175, 2008.

SIQUEIRAJR., J. B.; VINHAL, L. C.; SAID, R. F. C.; HOFFMANN, J. L.; MARTINS, J.; BARBIRATTO, S. B.; COELHO, G. E. Saúde Brasil 2010: uma análise da situação de saúde e de evidências selecionadas de impacto de ações de vigilância em saúde. 2010. Disponível em: <http://portal.saude.gov.br/portal/arquivos/pdf/ cap_7_saude_brasil_2010.pdf>. Acesso em: 19 fev. 2013.

SOUZA, A.; LEITE, J. C. J. A dengue no município de Santo Amaro: aplicação de geoprocessamento para diagnóstico e análise dos casos. In: CONGRESSO DE PESQUISA E INOVAÇÃO DA REDE NORTE NORDESTE DE EDUCAÇÃO TECNOLÓGICA, V, 2010, Salvador. Resumos. Salvador: CONNEPI, 2010. CDROM.

SPSS INCORPORATION. Statistical package for the social sciences - SPSS. v. 15. Chicago: SPSS INCORPORATION, 2012.

STATSOFT SOUTH AMERICA. Statistica, software de análise estatística. v. 8. São Caetano do Sul, 2012.

TAUIL, P. L. Urbanização e ecologia do dengue. Cadernos de Saúde Pública, Rio de Janeiro, v. 17, p. 99-102, 2001.

TAUIL, P. L. Aspectos críticos do controle do dengue no Brasil. Cadernos de Saúde Pública, Rio de Janeiro, v. 18, n. 3, p. $867-$ $871,2002$.

TEIXEIRA, M. G. Controle do dengue: importância na articulação de conhecimentos transdisciplinares. Interface - Comunicação, Saúde, Educação, Botucatu, v. 5, p. 442-451, 2008. 